\title{
Predictor Variables of Developing Anterior Pituitary Deficiencies in a Group of Paediatric Patients with Central Diabetes Insipidus and Langerhans Cell Histiocytosis
}

\author{
Elisa Vaiani ${ }^{a} \quad$ Carmen Malossetti $^{a} \quad$ Lina Margarita Vega ${ }^{a}$ Pedro Zubizarreta ${ }^{b}$ \\ Jorge Braier ${ }^{b}$ Alicia Belgorosky ${ }^{a}$ \\ ${ }^{a}$ Endocrine Service and ${ }^{b}$ Hematology-Oncology Service, Hospital de Pediatria Garrahan, Buenos Aires, Argentina
}

\author{
Keywords \\ Paediatric Langerhans cell histiocytosis · Anterior pituitary \\ deficiency · Diabetes insipidus
}

\begin{abstract}
Background: Langerhans cell histiocytosis ( $\mathrm{LCH}$ ) is a rare histiocytic disorder of unknown etiopathogenesis. Central diabetes insipidus (CDI) is the most frequent endocrine manifestation and is a known risk factor for the development of further anterior pituitary hormone deficiencies (APD). However, not all CDI patients develop APD, as observed during prolonged periods of follow-up. Aim: To find predictors of developing APD in LCH children with CDI followed in our institution. Methods: We retrospectively analysed 44 patients over a median period (quartiles) of 12.3 years (8.79-14.24). Patients were subdivided into group 1 and group 2, according to absence or presence of APD, respectively. The main variables studied were: (1) chronological age (CA) at LCH diagnosis, (2) the primary site of LCH at diagnosis: low risk (LR) and multisystemic risk organs, and (3) the presence of reactivation. Results: Multivariate Cox regression analysis showed that APD was positively associated with CA at LCH diagnosis [relative risk (RR) 1.14, $p<$ $0.01]$, the LR clinical form (RR 8.6, $p<0.03$ ), and negatively
\end{abstract}

associated with the presence of reactivations (RR 0.3, $p<$ $0.01)$. Conclusions: Patients with older CA at LCH diagnosis, LR clinical forms, and fewer reactivation episodes might represent a subgroup of paediatric $\mathrm{LCH} C \mathrm{CD}$ patients with a higher risk of developing APD.

(c) 2016 S. Karger AG, Basel

\section{Introduction}

Langerhans cell histiocytosis $(\mathrm{LCH})$ is a rare and heterogeneous disease, characterised by accumulation and clonal proliferation of immature dendritic cells (DC) in different organs, with features similar to epidermal Langerhans cells, and expressing antigen CD1a and/or CD 207 (langerin) on immunohistochemistry $[1,2]$.

LCH affects about 4.1-5 million children per year. More than $50 \%$ of cases are diagnosed between 1 and 15 years of age, with a peak between 0 and 4 years $[3,4]$.

Whether LCH represents a reactive or a neoplastic disease is still a matter of debate. Proinflammatory cytokines and chemokines are known to play a role in $\mathrm{LCH}$, suggesting that $\mathrm{LCH}$ is an immune disorder. However, the oncogenic $B R A F$ mutation is also detected in more than half of LCH patients [5]. Probably, LCH is the only patho-

\section{KARGER}

(c) 2016 S. Karger AG, Basel

E-Mail karger@karger.com

www.karger.com/hrp
Alicia Belgorosky, $\mathrm{PhD}, \mathrm{MD}$

Endocrine Service, Hospital de Pediatría Garrahan

Combate de los Pozos 1881

Buenos Aires ZC C1245AAM (Argentina)

E-Mail abelgo@ netizen.com.ar 
logic combination between oncogenesis and chronic immune dysregulation $[2,6,7]$.

Whatever the primary event, a number of LCH inflammatory cells ( $T$ lymphocytes, macrophages, plasma cells, eosinophils, osteoclast-like multinucleated giant cells, and neutrophils) and molecules (cytokines, chemokines, and $\mathrm{DC} /$ macrophage-activating factors) with different properties (regulatory, pro-inflammatory, apoptotic, and anti-apoptotic) is consistently present in LCH lesions and, to a certain extent, in the serum of patients with $\mathrm{LCH}$ $[2,8]$.

Most organs or systems of the human body can be affected, but those more frequently involved are the skeleton $(80 \%$ of cases), the skin $(33 \%)$, and the pituitary $(25 \%)$. Other organs involved are the liver, spleen, the haemapoietic system and the lungs (15\% each), lymph nodes (5-10\%), and the central nervous system (CNS), apart from the neurohypophysis (2-4\%) [1].

LCH can be classified according to system involvement as unisystem disease (US), which can be uni- or multifocal and is usually associated with a good prognosis and might require no treatment, or as multisystem disease (MS), which has a poorer prognosis and requires different therapeutic modalities, including cytotoxic drugs and corticoids. The majority of patients with MS have permanent sequelae [9].

Endocrine manifestations in $\mathrm{LCH}$ show a particular predilection for involvement of the hypothalam-pituitary axis, leading to central diabetes insipidus (CDI) and/or anterior pituitary dysfunction; these mainly develop in the context of MS $[10,11]$. CDI is the most frequent endocrinopathy associated with $\mathrm{LCH}$. The reported incidence is between $15-30 \%[1,12,13]$. CDI may become manifest either before, concurrent with, or after LCH diagnosis [14-16]. In addition, patients with DI have a high risk to develop further anterior pituitary hormone deficiencies (APD) during the course of the disease $[10,15]$. In keeping with these data, Donadieu et al. [17] described a 5- and 10-year risk of developing GHD of 34.7 and $53.7 \%$, respectively.

In order to find biological predictors of developing APD in LCH children with CDI, we describe the longterm follow-up in LCH children with CDI conducted at our institution from August 1987 to December 2014. We found that APD is more frequent when LCH begins at an older age. In addition, a low-risk clinical form of LCH (US, MS) and less reactivation episodes might represent a subgroup of patients with a higher risk of developing APD.

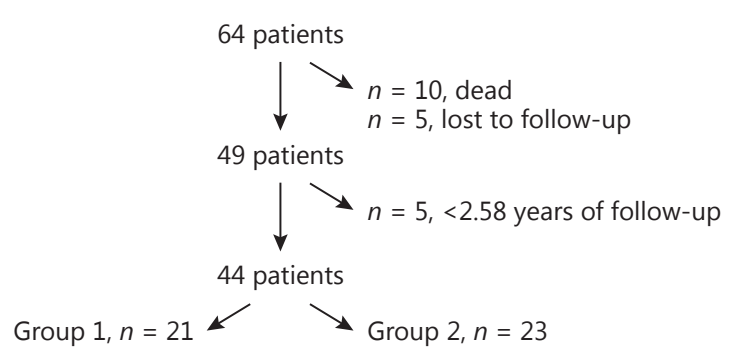

Fig. 1. Flow chart to indicate how subjects were selected for inclusion in the 2 groups: group 1: LCH CDI without APD. Group 2: LCH CDI with APD.

\section{Patients and Methods}

We retrospectively reviewed medical charts of 64 consecutive patients who were diagnosed with DI and LCH at our institution between August 1987 and December 2014. Patients were initially referred to our service with a suspected diagnosis of CDI. This study was approved by the Ethics Committee of the Garrahan Paediatric Hospital. Informed consent was obtained from parents and patients.

LCH diagnosis was confirmed by pathology studies, using both morphological and immunostaining criteria, including CD1a positivity according to the Histiocyte Society criteria. In agreement with the guidelines of the LCH study protocols [1], US was diagnosed when only 1 organ or system was involved. The disease was considered to be unifocal when just 1 site was affected and multifocal, when more than 1 site was involved. The disease was defined as being MS when 2 or more organs or systems were affected. In addition, MS was classified into 2 groups depending on whether risk organs (RO) were compromised.

RO were defined as those organs that, when they are compromised, increase the risk of dying from the disease. They are the liver, spleen, and/or the haematologic system. In these cases, the disease was considered to be $\mathrm{RO}+$. When the organs and systems affected were bone, skin, mucosa, lymph nodes, lungs, or CNS, considered as low risk (LR) organs, the disease was defined as RO-. Skull bone lesions, regarded as "CNS risk lesions" [1], involving the orbital, temporal, sphenoid, ethmoid, or mastoid bones as well as the paranasal sinuses and anterior or middle cranial fossa were documented.

Magnetic resonance images (MRI) at the time of diagnosis were obtained in 51 patients. Neurological abnormalities were categorised as thickening of the pituitary stalk and absence of the neurohypophysis. Tumour lesions were defined as space-occupying lesions involving the hypothalamic-pituitary region or other parts of the brain. These lesions were either isolated or in the context of MS. Radiotherapy applied to the hypothalamic-pituitary region was especially recorded to evaluate the possible effect of radiotherapy on hypothalamic-pituitary function. Disease reactivation was defined according to a previous report [11], and for the purpose of this study, it was considered when the patient had 1 or more new episodes during follow-up.
Horm Res Paediatr 2017;87:51-57 DOI: $10.1159 / 000452996$
Vaiani/Malossetti/Vega/Zubizarreta/ Braier/Belgorosky 
Table 1. Clinical features of $44 \mathrm{LCH}$ CDI children with a follow-up time $>2.58$ years and the 2 groups according to absence (group 1) or presence (group 2) of APD throughout the follow-up period

\begin{tabular}{|c|c|c|c|}
\hline Patients & Total & Group 1 & Group 2 \\
\hline Total number & $44(100)$ & $21(47.7)$ & $23(52.3)$ \\
\hline \multicolumn{4}{|l|}{ CA at LCH diagnosis, years } \\
\hline Median & 2.44 & 2 & $3.24^{*}$ \\
\hline Interquartiles & $1.7-5.01$ & $1.64-2.78$ & $2.1-6.4$ \\
\hline \multicolumn{4}{|l|}{ Clinical presentation } \\
\hline US UF & 9 & $2(9.5)$ & $7(30.3)$ \\
\hline US MF & 6 & $4(19)$ & $2(8.7)$ \\
\hline MSLR & 19 & $6(28.6)$ & $13(56.5)$ \\
\hline MSR & 10 & $9(42.9)$ & $1(4.3)$ \\
\hline \multicolumn{4}{|l|}{ MRI } \\
\hline Absence of neurohypophysis & $20(48.7)$ & $9(50)$ & $11(47.8)$ \\
\hline Thickening of the pituitary stalk & $18(43.9)$ & $8(44)$ & $10(43.4)$ \\
\hline Arachnoidocele/cyst & $2(4.8)$ & - & $2(8.6)$ \\
\hline Expansive lesions affecting the HP region & $4(9.7)$ & - & $4(17.3)$ \\
\hline Expansive lesions in brain or meninges & $4(9.7)$ & $2(11.1)$ & $2(8.6)$ \\
\hline Normal & $5(12.1)$ & $3(16)$ & $2(8.6)$ \\
\hline \multicolumn{4}{|l|}{ CDI diagnosis } \\
\hline LCH diagnosis prior & 7 & 1 & 6 \\
\hline LCH diagnosis simultaneously & 16 & 6 & 9 \\
\hline LCH diagnosis posteriorly & 22 & 14 & 8 \\
\hline \multicolumn{4}{|l|}{ Sex distribution } \\
\hline Male & $31(70.4)$ & $14(66.7)$ & $17(73.9)$ \\
\hline Female & $13(29.5)$ & $7(33.3)$ & $6(26.1)$ \\
\hline HP radiotherapy & $5(11.3)$ & $2(9.5)$ & $3(13)$ \\
\hline \multicolumn{4}{|l|}{ Follow-up, years } \\
\hline Median & 12.3 & 13.9 & 12 \\
\hline Quartiles & $8.79-14.24$ & $9.9-15.2$ & $6.1-14$ \\
\hline Reactivations & $22(50)$ & $14(66.7)$ & $8(34.8)^{* *}$ \\
\hline
\end{tabular}

Values are $n(\%)$, except where otherwise indicated. CA, chronological age; LCH, Langerhans cell histiocytosis; US, unisystem; UF, unifocal; MF, multifocal; MS, multisystem; LR, low risk; MRI, magnetic resonance imaging; HP, hypothalamic-pituitary; CDI, central diabetes insipidus. MSR was defined as those organs (liver, spleen, and/ or haematologic system) that, when they are compromised, increase the risk of dying from the disease. MRI ( $n=$ 21). ${ }^{*} p<0.01 ; * * p<0.04$.

\section{Endocrine Assessment}

Anterior pituitary involvement was considered when at least 1 pituitary hormone axis was affected and there were clinical signs and symptoms of hormone deficiency (polyuria/polydipsia, growth retardation, pubertal delay).

CDI diagnosis was made based on the water deprivation test according to a previous report [18]. GHD was defined as follows: maximum serum $\mathrm{GH}$ response less than $6.1 \mathrm{ng} / \mathrm{mL}$ (IRP IS80/505) or $4.7 \mathrm{ng} / \mathrm{ml}$ (IRP IS 98/5742) to 2 pharmacological tests $[19,20]$.

In agreement with a previously report [21], gonadotropin deficiency was defined as a low or absent serum FSH and LH response to an LHRH analog test at the pubertal age [chronological age (CA) $\geq 13$ or 14 years in girls and boys, respectively]. The hypothalamic- pituitary thyroid and adrenal axes were evaluated by determining serum basal T4, T3, fT4, and TSH, thyroid antibodies, and morning ACTH and cortisol levels, and/or the low-dose ACTH test, respectively [22]. Patients were assessed periodically at least once a year. The date of CDI and APD diagnosis was the date of the first abnormal test. To be considered the first isolated manifestation of $\mathrm{LCH}, \mathrm{CDI}$ had to be diagnosed at least 3 months before any extrapituitary involvement.

\section{Study Design}

Sixty-four consecutive CDI patients with $\mathrm{LCH}$ were included. Sex, CA at LCH, CDI and APD diagnosis, clinical form of $\mathrm{LCH}$ presentation, radiotherapy, and MRI findings were recorded. 
Time of follow-up was considered to be from CDI diagnosis until the last visit.

As shown in Figure 1 at the time of the study, 10 out of 64 patients were deceased (9 patients had disseminated $\mathrm{LCH}$ and 1 patient had an accident). Five other patients were lost to follow-up. Forty-nine patients were included in the follow-up analysis. For the analysis of follow-up data, patients were subdivided depending on the absence (group 1) or presence (group 2) of APD throughout the follow-up. Preliminary results on the time course of APD detection (online suppl. Fig. 1 and 2; for all online suppl. material, see www.karger.com/doi/10.1159/000452996) showed that 50\% had developed APD at a median of 2.58 years of follow-up. Therefore, for the long-term follow-up analysis we included only those patients with 2.58 or more years from CDI diagnosis (no LCH diagnosis). Based on this criterion, long-term follow-up was analysed in 44 patients (Fig. 1). In addition, in each subgroup of patients the following variables: (1) the primary site of LCH at diagnosis: LR (including US and MS disease and hypothalamic-pituitary CNS involvement) and MS RO+ (MSR), (2) under or equal to 2 years of age at $\mathrm{LCH}$ diagnosis, and (3) the presence of reactivation were also analysed.

\section{Statistical Analysis}

Statistical analysis was performed using the package Statistix 7 (Analytical Software, Tallahassee, FL, USA) Copyright ${ }^{\circledR} 2000$ Analytical Software. Categorical data were compared using the Fisher exact test and quantitative data with the Wilcoxon rank-sum test. A $p$ of $<0.05$ was considered to be statistically significant.

The Kaplan-Meier analysis was used to estimate APD-free survival rates. The end point for survival analysis was the first-time appearance of APD. The period taken into account was the interval between LCH diagnosis and an event of APD or the last examination when no event occurred. Survival was compared between groups using the log-rank rest. Proportional hazards regression was used to estimate the relative risk of developing APD associated with 1 unit increase for the independent variables.

\section{Results}

The clinical characteristics of the 64 patients with LCH associated with CDI are shown in online supplementary Table 1 . As previously described, 44 patients were included in the long-term analysis (follow-up group). Median follow-up after CDI diagnosis was 12.3 years (interquartile range, 8.7-14.2). The clinical characteristics of the patients in the follow-up group are shown in Table 1. The primary sites of $\mathrm{LCH}$ at diagnosis were as follows: 15 (34\%) patients had LR US disease and the remaining 29 (65.9\%) patients had MS disease. Within the MS group, 19 (43\%) patients had the LR clinical form and $10(22.7 \%)$ patients had MSR. Skull bone risk lesions were observed in $91 \%$ of the patients.

An initial MRI was performed in 41 patients, revealing the following findings: absence of the neurohypophysis $(n=20)$, thickening of the pituitary stalk $(n=18)$, arach-
Table 2. Proportional hazards regression for the event variable: "appearance of 1 APD episode during follow-up," in 44 LCH CDI patients

\begin{tabular}{lclrll}
\hline Variable & Coefficient & SD error & $\mathrm{Z}$ & p value & $\mathrm{RR}$ \\
\hline CA & 0.13 & 0.05 & 2.34 & $<0.01$ & 1.14 \\
Reactivation & -1.19 & 0.46 & -2.59 & $<0.01$ & 0.3 \\
LR & 2.15 & 1.03 & 2.08 & $<0.04$ & 8.6 \\
\hline
\end{tabular}

LCH, Langerhans cell histiocytosis; LR, low risk clinical form of LCH diagnosis unisystem and multisystem; CA, chronological age at LCH diagnosis; APD, antero-pituitary deficiency; CDI, central diabetes insipidus; $\mathrm{RR}$, relative risk.

noidocele/cyst (A) ( $n=2)$, expansive lesions (tumour lesions) affecting the hypothalamic-pituitary region only $(n=4)$, and the brain or meninges $(n=4)$. Five patients had a normal MRI.

For the long-term analysis, patients were subdivided into 2 groups: group $1(n=21)$ and group $2(n=23)$, according to the absence or presence of APD, respectively. The median CA (years) at LCH diagnosis was significantly higher in group 2 (3.24 years) than in group 1 (2 years) $(p<0.01)$. The primary sites of LCH at diagnosis were in group 1 and group 2, respectively, as follows: 6 (28.5\%) and $9(39.1 \%)$ had LR US disease, $6(28.6 \%)$ and 13 (56.5\%) had MS LR, and $9(42.9 \%)$ and 1 (4.3\%) patients had MSR. As was expected, APD was present in the 4 patients with an hypothalamic-pituitary tumour mass. The median time of follow-up after CDI was 13.9 years (interquartile range, 9.9-15.2) in group 1 and 12 years (interquartile range, 6.1-14) in group 2 (the $p$ value was not statistically significant). Sex distribution and radiotherapy were not different between groups. Reactivations during follow-up were significantly higher in group 1 (66.7\%) than in group $2(34.8 \%)(p<0.04)$.

In a Kaplan-Meier analysis, the comparative log-rank test showed a significant difference for the appearance of APD for age at LCH diagnosis ( $p<0.02$; Fig. $2 \mathrm{a}$ ), LR clinical forms ( $p<0.01$; Fig. $2 b)$, and absence of reactivation episodes (Fig. 2c) during the long-term follow-up $(p<0.01)$.

Multivariate Cox regression analysis confirmed that the appearance of APD was significantly associated with (1) higher CA at LCH diagnosis [relative risk (RR) 1.14, $p<0.01$ ], (2) fewer reactivation episodes (RR $0.3, p<$ 0.01 ), and (3) LR clinical forms at LCH diagnosis (RR 8.6, $p<0.037$ ) (Table 2). Similar results were obtained excluding patients with CNS tumours in the hypothalamic-pituitary region (data not shown).
Horm Res Paediatr 2017;87:51-57 DOI: $10.1159 / 000452996$
Vaiani/Malossetti/Vega/Zubizarreta/ Braier/Belgorosky 


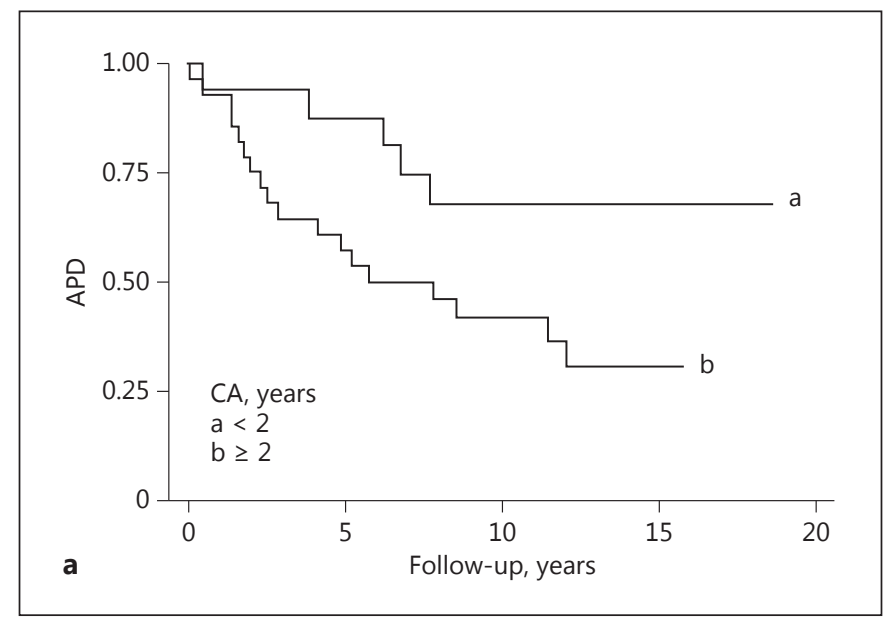

Fig. 2. Kaplan-Meier analysis for the appearance of $A P D$ as a function of CA (a) at LCH diagnosis (log-rank test: a vs. b, $p<0.02$ ), clinical forms: LR, MSR (log-rank test: a vs. b, $p<0.01)(\mathbf{b})$, and reactivation episodes (log-rank test: a vs. b, $p<0.01)$ (c).

Radiotherapy was not considered as a confounding variable, since there was a similar patient distribution within groups. In addition, very low radiotherapy doses were applied (10-15 Gy). GHD (45.4\%) and TSHD (34\%) were the most frequent APD associated with CDI, followed by gonadotropins deficiency (27\%) and ACTHD (9\%).

\section{Discussion}

This retrospective study of a large number of paediatric patients with $\mathrm{LCH}$, selected based on the presence of CDI, showed that APD is more common when LCH diagnosis is made at an older age, the clinical form at diagnosis is US or MS LR, and the disease has less reactivation episodes.

LCH was originally described as 3 different entities: eosinophilic granuloma, Hand-Schüller-Christian dis-

Paediatric LCH: Predictor Variables of Anterior Pituitary Deficiencies
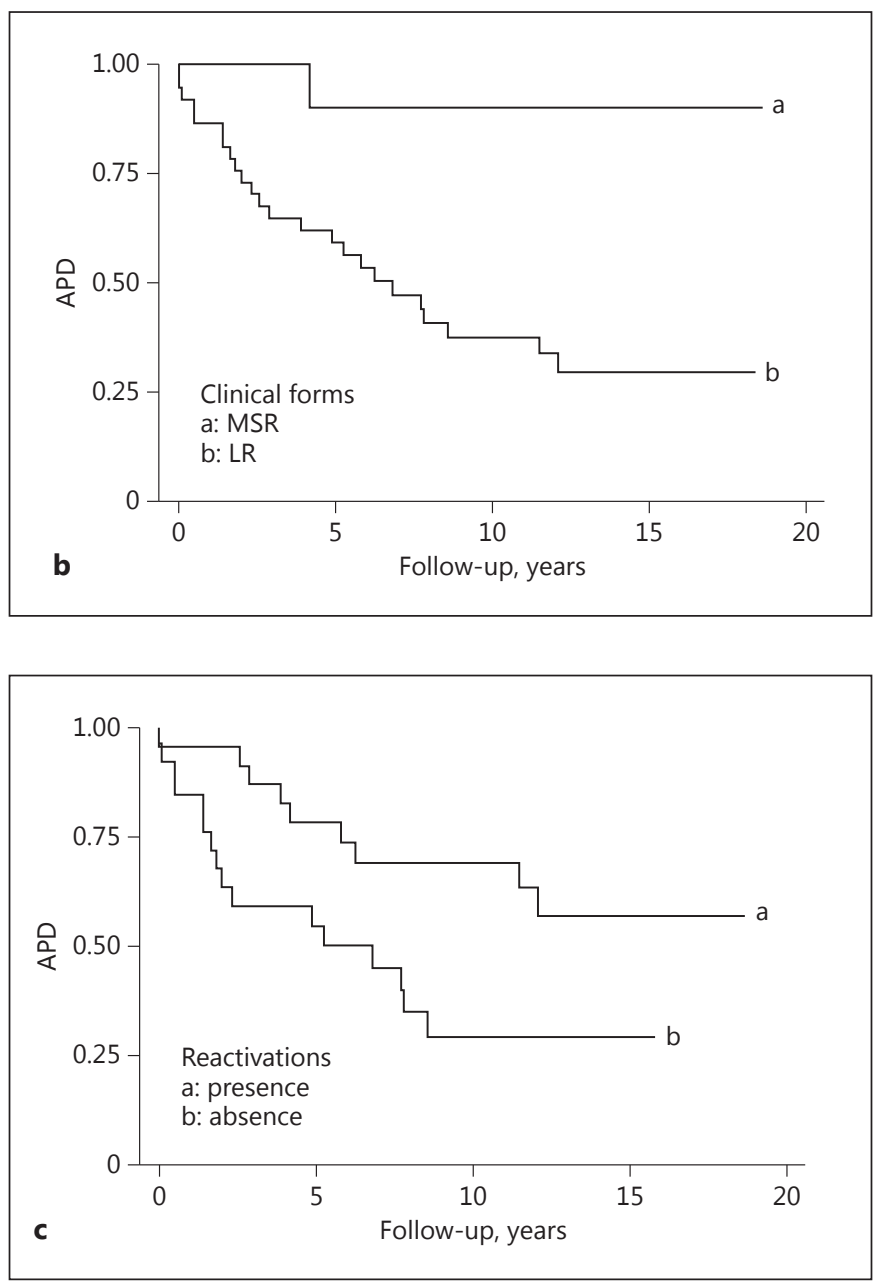

ease, and Letterer-Siwe disease. In 1953, Lichtenstein [23] identified the common pathology (abnormal histiocytes) of these 3 entities of unknown aetiology and proposed the name of "histiocytosis X" (HX) for them. Later on, Nezelof and Bassett [24] showed that the lesional histiocytes in HX share a common phenotype with the Langerhans cells of the normal dermis, and, more specifically, they bear the same unique intracytoplasmic body called "Birbeck granula". Since then, the term Langerhans cell histiocytosis gradually replaced HX. Although, a lot of progress has been made on $\mathrm{LCH}$, predominantly in its clinical characterization and management, the pathogenesis is still controversial.

In agreement with reports in the literature on risk factors for developing CDI $[1-3,11,13,17,25-27]$, in this study, a predominance of MS disease, skull bone risk lesions, and reactivation episodes was observed. It is well recognised that APD appears during the course of the dis- 
ease in patients affected by CDI $[10,15,17]$; however, and similar to the findings of another study [17], only 23 patients (52.2\%) developed APD during the long-term follow-up.

There is scarce information on the risk factors for developing APD, especially in LCH patients with CDI $[17,25,28,29]$. In a previous report [17], the authors described 2 early findings - premature loss of growth velocity and decreased anterior pituitary height on the MRI - as predictive variables for APD. Although we were not able to analyse these factors, using multivariate Cox regression analysis, we found 3 significant factors predictive of APD development: (1) older age at the diagnosis of LCH, (2) US or MS LR at the diagnosis of $\mathrm{LCH}$, and (3) less reactivation episodes during followup. Older age at the diagnosis of LCH could be explained by a delay in the diagnosis of this heterogeneous disease and, consequently, a deferral in treatment initiation. The latter situation might condition a different outcome of the same disease. On the other hand, the more frequent involvement of LR organs in the APD group may suggest a different pathogenic origin of DC. In keeping with these data, Berres et al. [30] postulated that the developmental stage of pathological DC precursors defines the extent of the disease and consequently the different clinical presentations. Interestingly, Donadieu et al. [31] stated that MSR LCH associated with haematologic and liver involvement was not associated with an increased risk of pituitary involvement either with CDI or APD.

Disease reactivations have been related to an increased risk of pituitary involvement $[11,13,31,32]$. Nevertheless, reactivations were significantly less in the APD group. The reason of this discrepancy might be related to the fact that in the analysis of CDI groups, the discrimination between the presence or absence of APD is frequently not included in data analysis.

A different embryological origin of the antero- and neurohypophysis may determine a different immune effect. The mechanism of APD is still poorly understood. However, different possibilities have been proposed, such as: (1) infiltration of the hypothalamic region causing both deficiencies of antidiuretic hormone and hypothalamic releasing factors and/or infiltration of the anterohypophysis, (b) microinjury leading to vascular impairment and scarring [33], and (c) immune modulation of cytokines from adjacent osseous lesions or an autoimmune effect $[13,34]$.

In agreement with the literature $[9,15,17,25,28,35]$, GHD was the most and corticotrophin-releasing hor-
mone-ACTHD was the least frequent APD. The occurrence of the involvement of the different pituitary lineages remains to be elucidated. Similar to an earlier report [15], the interval until the first APD in our patients occurred was within a median of 2.58 years after CDI diagnosis.

Even though the limitation of this study defining predictive factors for developing APD might be related to the length of follow-up and treatment protocols that varied throughout time, all patients included in the present study were followed up at the same institution.

\section{Conclusion}

In this retrospective study, we defined our patient population with $\mathrm{LCH}$ associated with CDI at risk of developing APD, differentiating them from those who persisted only with CDI during a long-term follow-up. Based on our findings, older CA at LCH diagnosis, US and MS LR clinical forms, and fewer reactivations episodes might represent a subgroup of patients with a higher risk of developing APD than LCH MS CDI patients with $\mathrm{RO}$ involvement that survived over a longterm follow-up.

Although our subgroups of paediatric LCH CDI patients with and without APD may represent different pathogenic origins or DC function, the molecular mechanism of this difference remains unknown.

\section{Acknowledgements}

The authors would like to thank Dr. Nora Saraco and Dr. Carolina Cernadas for their assistance in the study.

The study was supported by grants from Consejo Nacional de Investigaciones Científicas y Técnicas (CONICET), Fondo para la Investigación Científica y Tecnologica (FONCYT), Argentina.

\section{Disclosure Statement}

The authors have no conflicts of interest to disclose.
56

Horm Res Paediatr 2017;87:51-57 DOI: $10.1159 / 000452996$
Vaiani/Malossetti/Vega/Zubizarreta/ Braier/Belgorosky 


\section{References}

1 Haupt R, Minkov M, Astigarraga I, Schäfer E, Nanduri V, Jubran R, Egeler RM, Janka G, Micic D, Rodriguez-Galindo C, Van Gool S, Visser J, Weitzman S, Donadieu J; Euro Histio Network. Langerhans cell histiocytosis (LCH): guidelines for diagnosis, clinical work-up, and treatment for patients until the age of 18 years. Pediatr Blood Cancer 2013;60: 175-184.

2 Morimoto A, Oh Y, Shioda Y, Kudo K, Imamura T: Recent advances in Langerhans cell histiocytosis. Pediatr Int 2014;56:451-461.

3 Salotti JA, Nanduri V, Pearce MS, Parker L, Lynn R, Windebank KP: Incidence and clinical features of Langerhans cell histiocytosis in the UK and Ireland. Arch Dis Child 2009;94: 376-380.

4 Guyot-Goubin A, Donadieu J, Barkaoui M, Bellec S, Thomas C, Clavel J: Descriptive epidemiology of childhood Langerhans cell histiocytosis in France, 2000-2004. Pediatr Blood Cancer 2008;51:71-75.

5 Badalian-Very G, Vergilio JA, Degar BA, MacConaill LE, Brandner B, Calicchio ML, Kuo FC, Ligon AH, Stevenson KE, Kehoe SM, Garraway LA, Hahn WC, Meyerson M, Fleming MD, Rollins BJ: Recurrent BRAF mutations in Langerhans cell histiocytosis. Blood 2010;116:1919-1923.

6 Egeler RM, Annels NE, Hogendoorn PC: Langerhans cell histiocytosis: a pathologic combination of oncogenesis and immune dysregulation. Pediatr Blood Cancer 2004;42: 401-403.

7 Maria Postini A, del Prever AB, Pagano M, Rivetti E, Berger M, Asaftei SD, Barat V, Andreacchio A, Fagioli F: Langerhans cell histiocytosis: 40 years' experience. J Pediatr Hematol Oncol 2012;34:353-358.

8 Minkov M: Multisystem Langerhans cell histiocytosis in children current treatment and future directions. Pediatr Drugs 2011;13:7586.

9 Haupt R, Nanduri V, Calevo MG, Bernstrand C, Braier JL, Broadbent V, Rey G, McClain KL, Janka-Schaub G, Egeler RM: Permanent consequences in Langerhans cell histiocytosis patients: a pilot study from the Histiocyte Society-Late Effects Study Group. Pediatr Blood Cancer 2004;42:438-444.

10 Makras P, Alexandraki KI, Chrousos GP, Grossman AB, Kaltsas GA: Endocrine manifestations in Langerhans cell histiocytosis: trends in endocrinology and metabolism 2007; 18:252-257.

11 Pollono D, Rey G, Latella A, Rosso D, Chantada G, Braier J: Reactivation and risk of sequelae in Langerhans cell histiocytosis. Pediatr Blood Cancer 2007;48:696-699.

12 Dunger DB, Broadbent V, Yeoman E, Seckl JR, Lightman SL, Grant DB, Pritchard J: The frequency and natural history of diabetes insipidus in children with Langerhans-cell histiocytosis. N Engl J Med 1989;321:1157-1162.

13 Grois N, Pötschger U, Prosch H, Minkov M,
Arico M, Braier J, Henter JI, Janka-Schaub G, Ladisch S, Ritter J, Steiner M, Unger E, Gadner H; DALHX- and LCH I and II Study Committee: Risk factors for diabetes insipidus in Langerhans cell histiocytosis. Pediatr Blood Cancer 2006;46:228-233.

14 Prosch H, Grois N, Prayer D, Waldhauser F, Steiner M, Minkov M, Gadner H: Central diabetes insipidus as presenting symptom of Langerhans cell histiocytosis. Pediatr Blood Cancer 2004;43:594-599.

15 Nanduri VR, Bareille P, Pritchard J, Stanhope R: Growth and endocrine disorders in multisystem Langerhans' cell histiocytosis. Clin Endocrinol (Oxf) 2000;53:509-515.

16 Braier J, Chantada G, Rosso D, Bernaldez P, Amaral D, Latella A, Balancini B, Masautis A, Goldberg J: Langerhans cell histiocytosis: retrospective evaluation of 123 patients at a single institution. Pediatr Hematol Oncol 1999; 16:377-385.

17 Donadieu J, Rolon MA, Pion I, Thomas C, Doz F, Barkaoui M, Robert A, Deville A, Mazingue F, David M, Brauner R, Cabrol S, Garel C, Polak M; French LCH Study Group: Incidence of growth hormone deficiency in pediatric-onset Langerhans cell histiocytosis: efficacy and safety of growth hormone treatment. J Clin Endocrinol Metab 2004;89:604-609.

18 Dattani MT: Water deprivation test in Clinical Paediatric Endocrinology; in Brook CGD, Hindmarsh PC (eds): Tests in paediatric endocrinology and normal values. Blackwell, 2003, vol 4, pp 15-17.

19 Chaler EA, Rivarola MA, Guerci B, Ciaccio M, Costanzo M, Travaglino P, Maceiras M, Pagani S, Meazza C, Bozzola E, Barberi S, Bozzola M, Belgorosky A: Differences in serum $\mathrm{GH}$ cut-off values for pharmacological tests of $\mathrm{GH}$ secretion depend on the serum GH method. Clinical validation from the growth velocity score during the first year of treatment. Horm Res 2006;66:231-235.

20 Chaler EA, Ballerini GA, Lazzati JM, Maceiras M, Frusti M, Bergada I, Rivarola MA, Belgorosky A, Ropelato G: Cut-off values of serum growth hormone $(\mathrm{GH})$ in pharmacological stimulation tests (PhT) evaluated in short-statured children using a chemiluminescent immunometric assay (ICMA) calibrated with the International Recombinant Human GH Standard 98/574. Clin Chem Lab Med 2013;51:e95-e97.

21 Belgorosky A, Chahin S, Chaler E, Maceiras M, Rivarola MA: Serum concentrations of follicle stimulating hormone and luteinizing hormone in normal girls and boys during prepuberty and at early puberty. J Endocrinol Invest 1996;19:88-91.

22 Vaiani E, Maceiras M, Chaler E, Lazzati JM, Chiavero M, Novelle C, Rivarola M, Belgorosky A: Central adrenal insufficiency could not be confirmed by measurement of basal serum DHEAS levels in pubertal children. Horm Res Paediatr 2014;82:332-337.
23 Lichtenstein L: Histiocytosis X; integration of eosinophilic granuloma of bone, Letterer-Siwe disease, and Schüller-Christian disease as related manifestations of a single nosologic entity. AMA Arch Pathol 1953;56:84-102.

24 Nezelof C, Bassett F: From histiocytosis X to Langerhans cell histiocytosis: a personal account. Int J Surg Pathol 2001;9:137-146.

25 Maghnie M, Bossi G, Klersy C, Cosi G, Genovese E, Aricò MJ: Dynamic endocrine testing and magnetic resonance imaging in the longterm follow-up of childhood Langerhans cell histiocytosis. Clin Endocrinol Metab 1998;83: 3089-3094.

26 Weitzman S, Egeler RM: Langerhans cell histiocytosis: update for the pediatrician. Curr Opin Pediatr 2008;20:23-29.

27 Grois N, Flucher-Wolfram B, Heitger A, Mostbeck GH, Hofmann J, Gadner H: Diabetes insipidus in Langerhans cell histiocytosis: results from the DAL-HX 83 study. Med Pediatr Oncol 1995;24:248-256.

28 Windebank K, Nanduri V: Langerhans cell histiocytosis. Arch Dis Child 2009;94:904908 .

29 Fahrner B, Prosch H, Minkov M, Krischmann M, Gadner H, Prayer D, Grois N: Long-term outcome of hypothalamic pituitary tumors in Langerhans cell histiocytosis. Pediatr Blood Cancer 2012;58:606-610.

30 Berres ML, Merad M, Allen CE: Progress in understanding the pathogenesis of Langerhans cell histiocytosis: back to histiocytosis X? Br J Haematol 2015;169:3-13.

31 Donadieu J, Rolon MA, Thomas C, Brugieres L, Plantaz D, Emile JF, Frappaz D, David M, Brauner R, Genereau T, Debray D, Cabrol S, Barthez MA, Hoang-Xuan K, Polak M; French LCH Study Group: Endocrine involvement in pediatric-onset Langerhans' cell histiocytosis: a population-based study. J Pediatr 2004; 144:344-350.

32 Grois N, Fahrner B, Arceci RJ, Henter JI, McClain K, Lassmann H, Nanduri V, Prosch H, Prayer D; Histiocyte Society CNS LCH Study Group: Central nervous system disease in Langerhans cell histiocytosis. J Pediatr 2010; 156:873-881.

33 Maghnie M, Genovese E, Aricò M, Villa A, Beluffi G, Campani R, Severi F: Evolving pituitary hormone deficiency is associated with pituitary vasculopathy: dynamic MR study in children with hypopituitarism, diabetes insipidus, and Langerhans cell histiocytosis. Radiology 1994;193:493-499.

34 Scherbaum WA, Wass JA, Besser GM, Bottazzo GF, Doniach D: Autoimmune cranial diabetes insipidus: its association with other endocrine diseases and with histiocytosis X. Clin Endocrinol (Oxf) 1986;25:411-420.

35 Amato MC, Elias LL, Elias J, Santos AC, Bellucci AD, Moreira AC, De Castro M: Endocrine disorders in pediatric-onset Langerhans cell histiocytosis. Horm Metab Res 2006;38: 746-751.
Paediatric LCH: Predictor Variables of Anterior Pituitary Deficiencies
Horm Res Paediatr 2017;87:51-57 DOI: $10.1159 / 000452996$ 